\title{
Wellcome bid sees Grick archive return home
}

\section{Alison Abbott and Rex Dalton}

Francis Crick, co-discoverer of the doublehelical structure of DNA with James Watson, has sold his scientific archive to Britain's Wellcome Trust for just under $\mathfrak{£} 2$ million (US\$2.8 million).

The deal was struck after months of negotiations with at least one other bidder serving as a buyer for Jeremy Norman - a private collector based in Novato, California, who is accumulating a large archive of the history of molecular biology (see Nature 411,732-733; 2001).

The sum paid by the trust, which was bolstered by money from the UK national lottery fund, is understood to be the largest ever given for the archives of a living scientist. Crick's collection includes correspondence with other scientists, including Watson, together with his laboratory notebooks and drafts of articles and books.

The archive will be shipped to the trust's library in London from San Diego, where Crick, now 85, works part-time at the Salk Institute in La Jolla. He is donating a photocopy of the archive's contents to the University of Califonia, San Diego.

Norman's representative, Al Seckel, a neuroscientist at the California Institute of Technology in Pasadena, has helped to acquire many other items for the Norman collection. Seckel had been trying to set up a centre for the history of molecular biology at his home institute, where Watson once

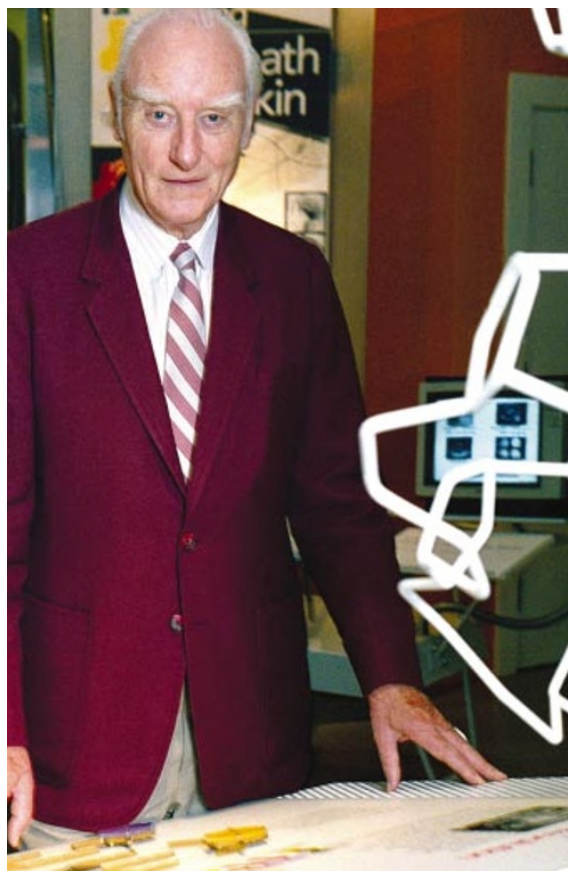

Record deal: Francis Crick's archive may be more expensive than that of any other living scientist.

worked, and hoped that Norman's collection could be included in it. Norman already owns papers from other eminent UK-based molecular biologists, including Maurice Wilkins, Max Perutz and Aaron Klug.

But many scientists, including Watson, have criticized privately held archives. Such archives, they say, could restrict access to scholars and are prone to being broken up when the collector dies. Watson is currently compiling his own archive at the Cold Spring Harbor Laboratory in New York state, where he is director.

Norman has denied these possibilities, but publicity about his archive has increased the pressure on scientists to donate their papers to public institutions. Crick is understood to have accepted slightly less from Wellcome than Norman had offered.

Norman declined to comment on the negotiations. "The Wellcome library is a very appropriate depository for Francis Crick's papers," he says.

But Seckel feels that the Wellcome arrangement has stymied his vision of a unified archive. "It would have been better to have all the relevant molecular-biology papers together, rather than segregate Crick's in a library that only collects English scientists' papers," he says. "This is not the way science operates - it is not nationalistic."

Meanwhile, the prices being sought for historically important scientific documents keep growing. For example, a signed singlepage proof from the 25 April 1953 issue of Nature is currently on sale by a rare-book dealer at an asking price of $\$ 43,500$. The page includes the famous Watson and Crick paper, as well as others by Wilkins and by Rosalind Franklin, whose X-ray crystallography helped to elucidate the structure of DNA.

\section{Jodrell Bank survives shake-up of UK astronomy}

\section{David Adam, London}

Faced with tough astronomy funding choices after deciding to join the European Southern Observatory (ESO), Britain has elected to retain its ageing Jodrell Bank telescopes and axe its commitment to several overseas observatories.

At a council meeting on 5 December, the Particle Physics and Astronomy Research Council (PPARC), which funds most of Britain's astronomy, agreed reductions of some $\mathfrak{E} 5$ million (US\$7.2 million) a year in its existing ground-based programmes to pay for its subscription to the Chile-based ESO project.

The cuts will affect observatories in Australia and Hawaii, as well as a cluster of optical telescopes at La Palma in the Canary Isles, where PPARC is pulling the plug on the Jacobus Kapteyn telescope and phasing out support for the Isaac Newton telescope.

But the biggest loser will be the AngloAustralian observatory at Sidings Spring in southern Australia, for which funding will be phased out altogether by 2007 .

"With a limited budget there will be inevitable reductions to certain facilities within the existing programme," says Ian Halliday, chief executive of PPARC.

The decision secures the immediate future of the MERLIN array of radio telescopes, including the 76-metre Lovell Telescope at Jodrell Bank in Cheshire, near Manchester. The network will now be refurbished with fibre-optic cable.

"The upgrade to MERLIN will ensure that our own national facility, centred around the Lovell telescope in the northwest, will continue to deliver world-class science," says Martin Rees, the Astronomer Royal.

It will also help to maintain the discipline's profile in Britain - the dish at Jodrell Bank is a national landmark, and is the astronomy programme's most powerful symbol.

Joining the ESO will give British astronomers access to the Very Large Telescope in Chile, as well as greater involvement in the Atacama Large Millimeter Array (ALMA), a network of 64 twelve-metre telescopes planned for construction there.

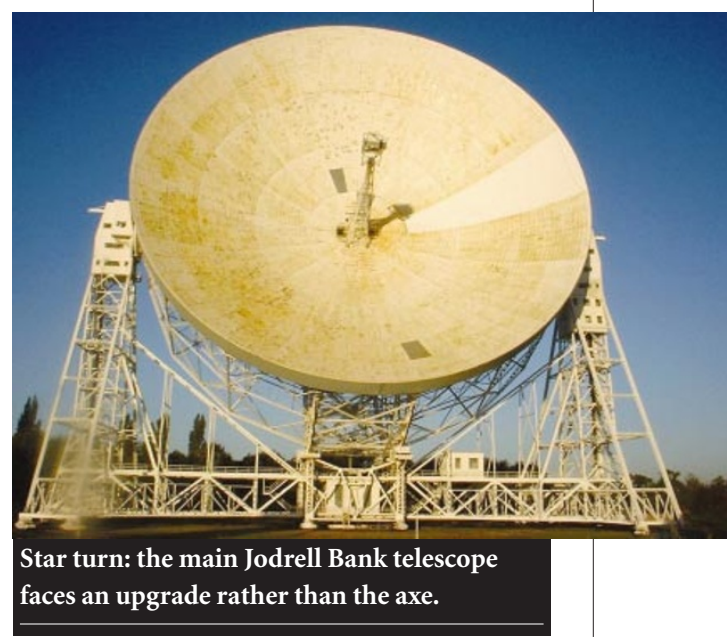

